\title{
Shaping the Adversary Culture
}

\section{Richard H. Gaskins Brandeis University}

\begin{abstract}
Our varied communities of discourse face a rhetorical future shaped by juridical styles reminiscent of the "adversary culture" postulated by post-war American critic Lionel Trilling. Itself the subject of litigious debate, the adversarial spirit today shows few signs of weakening, but its influence can be better understood and guided along certain tracks. To influence this adversarial style in coming decades, we need to explore the difference between evidencebased reasoning, which draws on the sensationalist logic of induction, and reflexive reasoning, which draws on the second-order logic of presumption. Understanding the structures and dynamics of this reflexive style forces us to address our responsibilities as speakers, as we seek to shape our rhetorical future. Close examination of adversarial conflict may lead us toward useful consensus on how the new game should be played.
\end{abstract}

Résumé: Nos diverses communautés de discours envisageront une rhétorique façonnée par des styles juridiques qui rappellent la "culture oppositionnelle" proposée par le critique américain de I'après-guerre, Lionel Trilling. Cette culture, sujette elle-même à des débats litigieux, montre peu de signes qu'elle s'affaiblit. Mais on peut mieux comprendre et guider son influence selon certaines voies. Si nous allons influencer ce style antagoniste dans les décennies à venir, nous devrons explorer la différence entre les raisonnements fondés sur l'expérience et la logique inductive, et les raisonnements réflexifs fondés sur la logique du deuxième ordre de la présomption. Une compréhension des structures et des dynamiques de ce style réflexif nous oblige d'assumer nos responsabilités comme interlocuteurs et interlocutrices qui tentent de façonner leur avenir rhétorique. Un examen minutieux des discours oppositionnels pourrait nous mener à un consensus utile sur la nouvelle approche rhétorique à adopter envers ces discours.

Keywords: adversary culture, Lionel Trilling, presumption, burden of proof, evidencebased reasoning, reflexive reasoning

Back in early March The New York Times carried a front-page story on the declining role of juries in the American legal process. Although it remains a powerful symbol of civic involvement, the American jury seems endangered in much the same way as the family farm: it thrives in the imagination but has virtually disappeared from the modern landscape. The Times reporter could scarcely conceal his alarm, blaming the loss on legislators, on appellate courts, and on "a legal culture that is moving away from trials as a method of resolving disputes." Most readers were probably disturbed by this news. Saturated with popular novels and courtroom TV dramas, most well-meaning Americans (including my own students at Brandeis) believe that most legal disputes in our country are resolved by juries. 
They cannot comprehend the actual numbers: today only $4.3 \%$ of federal criminal charges result in jury verdicts; the number of civil cases resolved by juries is down to $1.5 \%$.'

The Times reporter invites us to believe that something is fundamentally wrong with the American system of justice. But he never tries to show that juries are in fact capable of mastering the complex issues in criminal cases and civil lawsuits. Rather his argument rests on the tacit presumption that jury activity measures the true health of our democracy. A decline in jury activity, it follows, can comfort only the fascists and the autocratic elite. Is it time, then, for all freedom-loving Americans to run for cover? Should we consider emigration to more humane societies ... like Canada? Let's not be too hasty! Our intrepid reporter has already moved on to other projects, so maybe we can postpone any travel plans until the follow-up article appears next year, as it surely will.

In the meantime, let us apply his lament to a different purpose. It is indeed striking that the United States's legal system invests little importance in the precise task performed by juries: the determination of contested facts. For those of us who use jurisprudential analogies to clarify rhetorical practices, we must admit that American law cares little for this method of warranting factual conclusions. So-called questions of "fact" (the domain of juries) are overwhelmed by so-called questions of "law" (the domain of judges and appellate advocates). We still need facts, but we don't waste time vetting them: we acquire them mainly by stipulation, or by presumption. Instead of applying warrants to facts, our legal process channels its creative energy into framing alternative warrants. When we speak of the adversary system, we refer mainly to this second-order process of questioning the very rules of decision-making. Just as our legal culture has learned to live pretty much without juries, our broader public culture has learned to focus debate on second-order questions of method and process, beyond the surface issues of evidence and proof. This shift is what we might expect in a society that is loosening the bonds of consensus: where disagreements are shifting to more fundamental levels, and where pluralism is penetrating deeper into the value structure.

The idea that legal forms represent major currents in the broader culture is nothing new, although the relevant analogies appear to shift over time. As far as I can discover, the phrase "adversary culture" was first used in 1965 by the American literary critic, Lionel Trilling. Introducing his volume of essays entitled $B e$ yond Culture, ${ }^{2}$ Trilling worried about the influence of modern literary studies on everyday cultural practices. What will happen, he asked, to all the great works of modern literature-with their powerful message of rebellion and transgressionas they enter the standard curriculum at Columbia University, and from there (presumably) get released into the wider bourgeois atmosphere? Mind you, these were not Trilling's exact words; but he was obviously troubled by the uppermiddle class youth of the 1950 's - content with their "gentlemen C's," and standing on the brink of comfortable professional careers. What (if anything) will hap- 
pen to these students, he asked, as they encounter the subversive ideas of the great European novelists: Kafka, Mann, Gide, and Dostoevsky? What will happen to these students as they masticate and domesticate these modern ideas-and, more important, what will become of these ideas themselves, as they enter into everyday chatter around the corporate headquarters, around the law firm, and around the polo club? Trilling predicted the slow dilution of this critical literary heritage, fostered no-less by universities: "the socialization of the anti-social,...the aculturation of the anti-cultural, [and] the legitimation of the subversive." ${ }^{\text {3 }}$

As the 1960's wore on, Trilling's phrase became a neo-conservative mantra, invoked to lament the trend toward conflict and rebellion that so traumatized the New York intellectuals associated with Trilling and the Partisan Review. But Trilling's original concern was not to pin a negative label on the younger generation of rowdy dissenters. His worry (formed before the full Kulturkampf of the 1960's) was how the very act of rebellion might be weakened if and when it entered the standard rhetoric of public discourse. "Between the end of the first quarter of the century and the present time," he wrote in 1965, "there has grown up a populous group whose members take for granted the idea of the adversary culture." Although people may disagree on practical political goals, the adversary culture "generates its own assumptions and preconceptions, and contrives its own sanctions to protect them." Thus the days of rage and the domestic battles over Vietnam were entirely predictable cultural events. Equally predictable, to push Trilling's theory, was the co-opting of countercultural slogans, lifestyles, and hairdos by the broader public. For three decades television commercials have been fomenting personal rebellion, selling everything from luxury SUV's to distressed designer clothing.

Adversarial argument comes in many forms, but let me distinguish three modes for purpose of analysis. The first two have already been mentioned, and they roughly parallel the jurisprudential distinction between trial advocacy and appellate advocacy. Disputes about factual evidence are the stuff of famous trials, from Perry Mason to Johnny Cochran: from fingerprints to DNA, from the deceitful heiress to that glove that just didn't fit. The facts are in dispute, but the standards of measurement are fully stipulated. Here is a stolid universe of two-valued logicthe precondition for high drama, especially when the case gets submitted to that great black box called the jury. In this realm of the excluded middle, even a hung jury generates a specific result.

The second mode of adversarial argument is not about evidence as such, but about the warrants for judging evidence. Lawyers earn their salaries (more or less) by debating these arcane standards of due process, judicial standing, and doctrinal exceptions. Since the 1960's (perhaps initially to torment Lionel Trilling), academic disciplines have heartily embraced this second-order mode of discourse. Kuhnian paradigms reframed the classic debates from the history of science. Erving Goffman's theories of framing deconstructed the tacit conventions of daily behavior. The francophile theorists of deconstruction decentered the traditional arguments 
of dead philosophers; and the procession of radical turns keeps on gyrating through our own topsy-turvey times. Most of us came to intellectual maturity during this period, and at least some of us have trained our critical faculties on utterly helpless targets of such revolutionary shape-changing.

In this wide-ranging domain the principle of excluded middle gets pushed aside. The reductionist battle over facts is replaced by constructivist flights of argumentation. The raw empirical vision is exchanged for a special transcendental process that I have described elsewhere as resting on arguments from ignorance- - on skillful manipulations of presumptions and proof burdens. ${ }^{5}$ At this level, mere evidence is never enough to resolve adversarial conflict. Here is the true model for our contemporary adversary culture, now widely dispersed from remote academic circles to feed the revolutionary fervor of popular culture. As Lionel Trilling might ask, what will happen to our daily lives when hot new dot.com enterprises deconstruct the old economy, and when some bold new commercial fragrance challenges the prevailing olfactory paradigm?

These distinctive second-order arguments thrive especially in the ecological niches opened up by modern institutional structures. Consider, for example, the discourse strategies found in complex organizations. Perhaps most of us imagine organizational life as we find it in our respective universities - known in the sociological literature as "organized anarchies." More typical of contemporary organizations, for most North Americans, are business corporations, public bureaucracies, and voluntary associations. The old Weberian theory of bureaucracy treated these structures as the modern prototype of rational action, where formal goals and strategic action mimic the tight logical connection of ends and means. A popular rhetoric of organizational rationality nurtured these large enterprises throughout the past century, including the recent frenzy of corporate maneuvers known variously as restructuring, reengineering, and reinventing. Even universities came to embrace rational planning models: driving professors to spend years of committee time writing mission statements, lists of high-minded goals and objectives, and sweeping strategies supposedly derived from those guiding aims-all of it a utopian fancy that quickly turned into ritual and charade.

You may recognize this utopian promise of rational collective behavior as an institutional analogue to formal logic. The rational organization and the rational syllogism share a common ideal, in that both identify authority with a bloodless rigidity, rising beyond the frailties of practical judgment. Tied inexorably to this rhetorical model, administrative authority rests insecurely on an Aristotelian ideal of demonstration. In practice, large organizations face a whole range of external and internal challenges that keep them from ever approaching such fanciful expectations: challenges that are fully described in the sociological literature under the headings of uncertainty, ambiguity, and complexity of collective action.

An especially useful work in this genre is Swedish sociologist Nils Brunsson's analysis of organizational hypocrisy, ${ }^{6}$ which is his inspired term for the skillful 
simulation of rationality-that institutional pageant of symbol and ceremony, otherwise called "business as usual." As Brunsson shows, most organizations learn to avoid being judged under purely logical standards of legitimacy. They prefer to be judged, not by their actions, but by their internal procedures and ideologies, which place them on a simulated pathway to perfection. In universities, for example, strategic plans are always much too vague to determine concrete policies, but they foster the useful public image of universities as goal-centered, entrepreneurial, and worthy of philanthropic support. Three cheers for organizational hypocrisy!

It strikes me that organizational structures, in their compromised aspirations to authority and legitimacy, have nurtured our adversary culture-especially as our lives are increasingly governed by institutional decisions. A common mode of rhetorical opposition emerges within and around organizations, given the inevitable gap between ends and means, between the formal ideal on which institutional authority rests and the practical compromises that enter into implementation at every turn. One dominant theme of popular discourse, cultivated within organizational settings, is suspicion of hierarchy, and suspicion of the subtle power to translate static goals into living procedures. In earlier times-perhaps even in Weber's Germany-there may have been sufficient deference to elite judgment to buttress the rational image of corporate action. But today absolutely everyone knows how to attack "big business" and "big government." Above all, critics know to attack organizational decisions by emphasizing the gap between ends and means. Today every administrator expects to hear complaints that he or she failed to follow procedures; but the defense is always tricky, and it risks further charges of injustice.

Followers of the Frankfurt School will recognize this sociological application of rhetorical concepts. Standing on the shoulders of Max Weber, practically anyone can mount a fundamental critique of practically any manifestation of collective action. That, alas, is the problem. Unless we are still waiting for the fundamental revolution to take place, most of us understand that we live in a complex world, filled with uncertainties and ambiguities, and populated by large collective bodies. We require no reminders from Dostoevsky or Marx or Kafka to guide our adversarial ventures.

We practice the familiar rituals of dissent with simple ease; but it is not nearly so simple to hold our critique within practical limits. In response to the daily slights of bureaucratic society, we need also to practice measured opposition and a constructive ability to move on. But organizations seem to lack internal means for restoring this balance, as the rituals of opposition gather rhetorical strength. The challenge is not to silence opposition within organizations, but to make bureaucratic authority more reflective and responsive. Strategic hypocrisy is a step in the right direction, when it creates room for flexibility and change. But organizations also need to strengthen recursive modes of discourse, to keep the adversarial challenge from destroying institutional unity. 
In addition to organizational settings, second-order adversarial arguments are found on the rhetorical battlefields of modern risk analysis. Issues of personal health and safety always rank high on the scale of public concern, and everywhere we look we uncover ominous threats to a long and happy life. We are now accustomed to news stories about the ravages of underinflated Firestone tires, about airbags that kill undersized adults and children, and of course about the potential human consequences of mad cow disease. Highly speculative threats are widely discussed in the press: reproductive harms from genetically altered foods, brain cancer from cellphones, leukemia from power lines and contaminated drinking water. Even before these contemporary threats caught our attention, people were generally alert to issues of health and safety. The rise of statistical thinking in the nineteenth century accompanied the science of public health, with its evidencebased approach to controlling the incidence of disease. Danger started to come under human control, as empirical study revealed the human and natural sources of risk, and pointed toward rational methods for controlling it.

In an adversary culture, human responses to risk take on entirely new dimensions, driven by the sheer quantity of risk factors we may uncover. Since WWII, as petrochemicals transformed industrial production, as transportation narrowed distances between previously isolated communities, and as new information technologies expanded our knowledge base, our relationship to risk has grown far more complex and indeterminate. Is the troubling incidence of childhood asthma caused by genetics, or by urban pollution? is the prevalence of lower back pain due to ergonomically deficient workstations, or to our fondness for recreational sports? Do guns kill people, or do people kill people? Professional risk assessors armed with statistical tools and ceremonial trust in empirical testing are invited to address these unanswerable questions. Their budgets may be huge, but their answers are slow in coming; and we are all impatient for answers.

Debates over risk management have now reached the rhetorical level of appellate arguments, where experts champion competing frameworks for defining risk, and the general public chooses up sides. It might be different if all we cared about was a single threat from a known and controllable source, for which empirical research could find an acceptable remedy. For decades we hoped to control flu epidemics, and eventually medical research found an effective vaccine that could be mass produced. In the 1970 's, however, during the phantom swine flu epidemic we learned that flu vaccine, tragically, could itself become the source of crippling injury and death in a small percentage of cases. How do we compare the speculative risk of a major pandemic against the statistically assured risk to a random group (less than 1\%) of the innocent public? This damned-if-you-do-ordon't condition has set the tone for risk management debates over the past quarter century. It has generated conflicting research frameworks, aggressive political strategies, and a chequered rhetorical landscape.

Statistical thinking came of age during the nineteenth century, in large part, for 
the strategic purpose of controlling health and safety risks. Statistics expanded the reach of empirical inquiry, using new forms of evidence to override conventional beliefs. It postulated vast new realms of uncertainty, but offered practical tools for taming that uncertainty with standards modeled on sensory observation. Today, however, we must contend with a far greater number of potential risks--including risks of offsetting action and inaction-as well as reciprocal risks that lead to zero-sum battles between interest groups. Statistical methods generate multiple and conflicting hypotheses, as we know from trying to sort through the debate on global warming. Techniques like cost-benefit analysis play an additional strategic role, attempting to sway the balance of power in the empirical courts of facts and evidence. These economic gambits face stiff resistance in the higher tribunals of ethics and deep ecology, guided by prudential maxims like the burden-shifting "precautionary principle." Into this adversarial maelstrom flows a raging torrent of facts, providing raw energy for the interpretive battles taking place in the appellate jurisdictions of law and public opinion. Type I error challenges Type II error; where new factual evidence only increases the intensity of the dispute. More often than not, victory depends on who bears the burden of proof.

So this is life in an adversary culture. As lay advocates in this system of claims and counterclaims, we come forward as heroic amateurs to challenge the prevailing standards of expert judgment, and as discerning critics to challenge the tacit standards of social convention. By now everyone understands the strategic surge that comes from shifting mundane disputes to a higher tribunal, situated in some self-appointed jurisdiction. "Our opponents may prevail on the facts, but let's see if they can survive this rhetorical change of venue." As Trilling would remind us, however, the fact that everyone seems prepared to make this second-order shift dilutes any lasting strategic advantage. Instead of resolving disputes, these higher appeals may lead to endless jurisdictional battles, to the fragmentation of authority, and thus to inconclusive results that transform seemingly minor arguments into the clash of incommensurable systems.

After all is said and done, what lies ahead for our adversary culture? Is it a rhetorical encumbrance that we should try to cast off? The term "adversary culture" began as a mildly condescending phrase about the popular contamination of high-cultural notions. Soon it became a weapon in the culture wars of the 1960's, and it remains as a lament on the zealotry of the U.S. lawsuit industry. In this article I have applied the concept to more fundamental rhetorical patterns: notably the tendency for everyday arguments to shift into second-order strategic conflicts. Since the courts of public opinion lack a definitive appeals structure, these conflicts take on a frustrating, open-ended quality. In terms of argumentation theory, most of these strategic sorties fly under the radar of discourse ethics, pragma-dialectics, speech-act theory, and other ideal-type models. But assuming we can persuade argumentation theory to explore the ethnographic features of this cultural practice, what should be our larger goal? Should we try to stamp out this expression of adversary culture? To reform it? Or perhaps to reshape it? 
My preference is to follow an incremental strategy of studying and shaping the current mode of adversary discourse. I believe the strategic turn to second-order arguments is both real and irreversible, and in many ways highly desirable. To summarize my earlier points, I believe the impetus for this rhetorical style comes from the many uncertainties of both facts and values that surround collective action in modern societies, and from the resulting plural possibilities for future action. The past century saw the growth of complex organizational structures in our politics, in our economy, and in our society at large-structures designed to control complexity and to keep human beings focused and productive. Around the edges of these structures, and within their interstices, the presumptive rules find endless possibilities for variation and adaptation. We want these rules to be questioned in many specific ways, and by many different people, but not in such wholesale terms that would undermine the entire normative structure.

The same cautious approval can be given to the emerging field of social risk assessment, where the adversary style works effectively to expand research hypotheses in promising ways. In particular, the environmental movement and controversies like the global warming debate have challenged more passive notions of risk assessment. And yet I worry that some radical features of environmentalism could undermine collective efforts to control new forms of risk, by undercutting the entire concept of risk analysis.

In both fields of public debate, I believe that second-order arguments are here to stay. I even think we should welcome these arguments, but we should also map their distinctive rhetorical properties and try to shape them to the specific contours of pluralistic communities. This leaves me somewhere in the middle of the political-cultural spectrum. By contrast, Trilling's neo-conservative followers took a more terrified view, seeing the shift to second-order argument as an uncontrollable "crisis of values," which would slide inexorably into adversarial anarchy. They quickly renewed their faith in first-order factual argument, and indeed built that faith into a rhetorical fortress. At the other extreme, the post-modernist intelligentsia celebrated the freedom of second-order argument, and many encouraged the flirtation with anarchy. They seemed happy to sacrifice the closure of arguments, opening up a rhetorical stream that has never stopped flowing-and never will. My search for a moderate path wants to avoid both of these extremes. My position does not pretend to prove itself, nor does it rest on any transcendental axioms or demonstrations. It expresses my personal hope that we can expand the areas of common ground between today's most vocal adversaries, using analysis and critique.

What sort of analysis do I mean? I hope that argumentation theory can focus more directly on the elusive reflexive dimensions of adversarial debate, most of which lie buried in the presumptions of indirect discourse. To gain short-term strategic advantage, second-order arguments tend to suppress a whole substructure of presumptions. In other words, these arguments mask the critical basis for 
supporting their own affirmative claims. Reflexive critique may restore that critical structure in specific detail. (My model presupposes a dialectical structure of communication, taking that concept in its Hegelian sense. ${ }^{7}$ ) Whenever we challenge the very standards of evidence used by our opponents, we must anchor that challenge with some affirmative standard of our own, whether or not we choose to reveal it. Before securing any long-term victory, it is not enough to perfect the strategy of rejecting our opponent's critical venue. Every such rejection carries its own presumptions, which can be revealed only be rejoining the specific context in which the dispute first arose.

In most current adversarial discourse, with its emphasis on short-term victory, such reflexive moves are rare indeed. It is up to the parties to identify sufficient long-term interests in recursive self-examination, through which one might still challenge the status quo without undercutting the entire reach of legitimacy. In an appellate court, we look to a panel of judges, informed by the arguments of an equally skilled adversary, to supply this essential balance in the clash of strategic alternatives. Outside the courtroom-in the broader jurisprudence of public discourse-the adversary style runs the danger of overshooting its target, unless it reengages its opponent by returning the debate to its contextual origins.

Take, for example, the hard-nosed economist, out to challenge defenders of the Kyoto Treaty, ready to put a high price tag on future compliance with energyreduction targets, and warning that the American way of life is being put at risk. In such confrontations, the rhetorical posture presupposes two incommensurable types of calculation: the concrete dollars-and-cents of resource economics as opposed to the extrapolations from fuzzy climate models. The economist automatically "wins" if the dispute can be shifted to the jurisdiction of dollars-andcents. And yet this jurisdiction contains its own severe limits, including its own extrapolations from formal models of technology and human behavior. Both sides of the debate, in fact, need to address the implied limits of their respective efforts to set the criteria for public discourse. The deep ecologists, similarly, need to fill in the details of how human society will thrive in that utopian jurisdiction where all economic calculation is banished. At first blush their uncompromising norms may attract a wide group of followers; but most of us will probably turn back, once we see the operational details, to search for broader middle ground.

What 1 am proposing sounds like unilateral disarmament in the midst of a rhetorical Cold War. Indeed, for strategic reasons, we all want to protect our preferred standard from critical examination, while we conduct the rhetorical equivalent of nuclear war on our opponents. We couch our implicit standards in universal terms like "justice" and "fairness," and then shift the burden of proof to our opponents to demonstrate that they are not unjust, and not unfair. This strategy has been used to great effect in the field of constitutional law, where it inspired a revolution in the rules of criminal procedure, and where it has brought state bureaucracies under the power of aggressive judicial review. In the appellate courts 
of public discourse, however, the standards of justice and fairness have been appropriated by just about every conceivable interest group. In the environmental debate, the "environmental justice" movement borrows constitutional standards of equal protection; while the "wise use" movement, at the other end of the spectrum, claims exclusive dominion over fairness and due process. Even though I have greater sympathies for the former group, I am uneasy in the rhetorical landscape created by both. In my view, it is not enough to preach transformation and then move to a rhetorical jurisdiction of your own choosing. Indeed, the more revolutionary your critique, the greater your responsibility to explore the limits of your alternative standard.

In the end, I am pleased to live in an adversary culture, but I hope all of us can learn to shape it in more productive ways. Earlier in this article I suggested there were in fact three modes of adversarial argument. Here, at last, is my triadic scheme for interpreting such conflicts. First-order battles occupy the traditional field of evidence-based argument, while second-order disputes display a more free-floating appeal to higher standards, which may or may not be shared by opponents. The third level in this progression is a reflexive move-in some sense a step backwards. Rather than outflanking one's opponent with jurisdictional shifts, this reflexive move reconnects both partners and narrows the distance between their critical perspectives. Second-order reasoning works by suppressing the specific context of opposition. Bringing that opposition back to its contextual source rejoins the adversaries on common ground, while extending the horizons of both parties. Evidence and facts may once again come into play, and indeed the range of data is likely to expand.

So I close with this contrived scene of hermeneutic peace and harmony. Perhaps the jury is still out on whether these reflexive moments truly exist, let alone whether we can institutionalize them. I appear to have brought thematic closure to this article, but it remains only a strategic response to the sometimes bitter trials of an adversary culture. Much work needs to be done to reshape this strategic environment-to preserve it in some respects, but to restrain it from becoming its own worst enemy.

A rgumentation theory can certainly help, but it will have to move beyond static models of ideal communications - variously conceived as ethical, pragmatic or dialogical analysis. To breathe new life into the discipline, we must explore the strategic excesses of current discourse. In these very patterns of excess lie the tools for reshaping the adversary culture into something equally vibrant, but more likely to endure in a pluralistic world. 


\section{Notes}

1 "Juries, Their Powers Under Siege, Find Their Role is Being Eroded," William Glaberson, New York Times, March 2, 2001, p. A1.

${ }^{2}$ New York: Harcourt Brace Jovanovich.

Ibid., p. 23.

${ }^{4}$ Ibid., pp. ix, xi.

'See my Burdens of Proof in Modern Discourse (New Haven: Yale University Press, 1993).

"The Organization of Hypocrisy: Talk. Decisions and Actions in Organizations (Chichester: Wiley, 1989).

${ }^{7}$ This model is described at some length in chapter 8 of Burdens of Proof. Hegelian dialectic has had little impact on recent argumentation theory, but its embedded reflexive procedures draw out the implicit context of second-order reasoning (much of which is lost in other "dialectical" approaches)

Richard H. Gaskins Legal Studies Program

Brandeis University 415 South Street

Waltham. MA 02454 gaskins@brandeis.edu 